\title{
SOEP
}

$\int_{\text {SOEPpapers }}$

on Multidisciplinary Panel Data Research

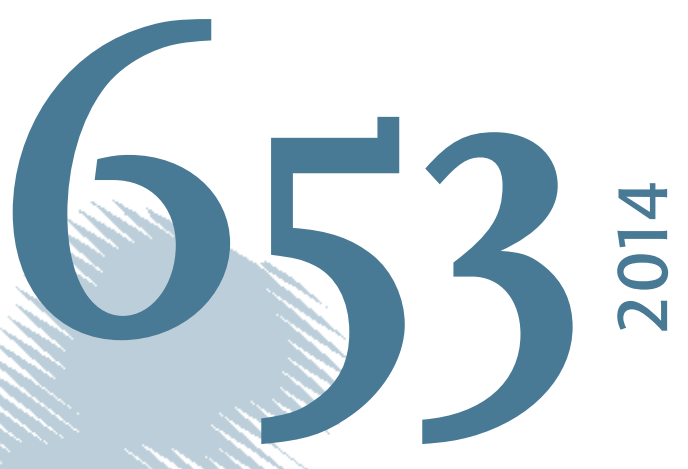

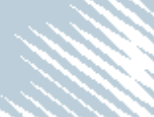

\section{Do Immigrants Bring Good Health?}




\section{SOEPpapers on Multidisciplinary Panel Data Research}

at DIW Berlin

This series presents research findings based either directly on data from the German SocioEconomic Panel Study (SOEP) or using SOEP data as part of an internationally comparable data set (e.g. CNEF, ECHP, LIS, LWS, CHER/PACO). SOEP is a truly multidisciplinary household panel study covering a wide range of social and behavioral sciences: economics, sociology, psychology, survey methodology, econometrics and applied statistics, educational science, political science, public health, behavioral genetics, demography, geography, and sport science.

The decision to publish a submission in SOEPpapers is made by a board of editors chosen by the DIW Berlin to represent the wide range of disciplines covered by SOEP. There is no external referee process and papers are either accepted or rejected without revision. Papers appear in this series as works in progress and may also appear elsewhere. They often represent preliminary studies and are circulated to encourage discussion. Citation of such a paper should account for its provisional character. A revised version may be requested from the author directly.

Any opinions expressed in this series are those of the author(s) and not those of DIW Berlin. Research disseminated by DIW Berlin may include views on public policy issues, but the institute itself takes no institutional policy positions.

The SOEPpapers are available at

http://www.diw.de/soeppapers

\section{Editors:}

Jürgen Schupp (Sociology)

Gert G. Wagner (Social Sciences, Vice Dean DIW Graduate Center)

Conchita D'Ambrosio (Public Economics)

Denis Gerstorf (Psychology, DIW Research Director)

Elke Holst (Gender Studies, DIW Research Director)

Frauke Kreuter (Survey Methodology, DIW Research Professor)

Martin Kroh (Political Science and Survey Methodology)

Frieder R. Lang (Psychology, DIW Research Professor)

Henning Lohmann (Sociology, DIW Research Professor)

Jörg-Peter Schräpler (Survey Methodology, DIW Research Professor)

Thomas Siedler (Empirical Economics)

C. Katharina Spieß (Empirical Economics and Educational Science)

ISSN: 1864-6689 (online)

German Socio-Economic Panel Study (SOEP)

DIW Berlin

Mohrenstrasse 58

10117 Berlin, Germany

Contact: Uta Rahmann | soeppapers@diw.de 


\title{
Do Immigrants Bring Good Health?
}

\author{
Osea Giuntella* \\ University of Oxford, IZA \\ Fabrizio Mazzonna ${ }^{\dagger}$ \\ University of Lugano, MEA
}

Draft

April 28, 2014

\begin{abstract}
This paper studies the effects of immigration on health. We merge information on individual characteristics from the German Socio-Economic Panel (1984-2010) with detailed local labour market characteristics and exploit the longitudinal component of the data to analyse how immigration affects the health of both immigrants and natives over time. Upon their arrival, immigrants are found to be healthier than the natives (healthy immigrant effect), but their health deteriorates over time spent in Germany. We show that the convergence in health is heterogeneous across immigrants and occurs more rapidly among those working in more physically demanding jobs. Immigrants are significantly more likely to work in strenuous occupations. In light of these facts, we investigate whether changes in the spatial concentration of immigrants affect the health of the native population. Our results suggest that immigration reduces the likelihood that residents report negative health outcomes. We show that these effects are concentrated in blue-collar occupations and are larger among low educated natives and previous cohorts of immigrants. The improvement in the average working conditions and workload of natives contributes to explain the positive effect of immigration on the health of the native population.
\end{abstract}

\section{Keywords: Health, immigration, occupational choice JEL Classification Numbers: I12, J24, J61}

${ }^{*}$ University of Oxford, Nuffield College. Blavatnik School of Government, 10 Merton Street, OX14JJ, Oxford, Oxfordshire, UK. Email: osea.giuntella@bsg.ox.ac.uk.

${ }^{\dagger}$ University of Lugano. Department of Economics, via Buffi 13, CH-6904, Lugano. Email: fabrizio.mazzonna@usi.ch. Rafael Gruber provided precious research assistance. We are thankful to Catia Nicodemo and Raphael Parchet for their comments and suggestions. We are also grateful to participants at workshops and seminars at the University of Lugano, the University of Oxford, the 2013 Immigration in OECD Countries Conference, the MEA at Max Planck Institute for Social Law and Social Policy, and the 2014 Royal Economic Society Conference. 


\section{Introduction}

In the public debate immigration is often blamed for increased healthcare costs and taxpayer burden. At the same time, empirical evidence shows that immigrants are typically young and relatively healthy and, therefore, less likely to use health care than natives (Goldman et al., 2006). Indeed, a voluminous set of studies provides evidence of a "healthy immigrant effect". Upon arrival immigrants are healthier than their population of origin and than natives, but their health deteriorates with time spent in the host country. These paradoxical facts are observed across several countries and different metrics of health (Kennedy et al., 2006; Antecol and Bedard, 2006; Chiswick et al., 2008). Shedding light on these health patterns is crucial to evaluate the costs and benefits of migration, and, in particular, its impact on health care costs. Yet, the mechanisms underlying immigrant health trajectories are not fully understood.

Previous work analysing the "healthy immigrant effect" focused on selection, behaviours and return migration as possible factors underlying the convergence observed in immigrants' health (Giuntella, 2013; Antecol and Bedard, 2006; Chiswick et al., 2008; Jasso et al., 2004). Surprisingly, the relationship between working conditions and the health trajectories of immigrants has been largely ignored by previous studies. However, there is the evidence that immigrants are more likely to work in riskier occupations, and to have worse work schedules than natives (Orrenius and Zavodny, 2012, 2009; Giuntella, 2012). In addition, several studies show that physical requirements and environmental conditions have negative effects on health (Case and Deaton, 2005; Fletcher and Sindelar, 2009; Fletcher et al., 2011; Ravesteijn et al., 2013). In this paper, we hypothesise that the sorting of immigrants in more strenuous occupations contributes to the observed deterioration in the health of immigrants. Furthermore, we analyse whether immigration, increasing the supply of healthy low skilled workers and leading natives to shift towards better working conditions, improves the health of natives and previous cohorts of immigrants.

While there exists a voluminous literature on the effects of immigration on wages, employment and prices (Card, 1990; Hunt, 1992; Friedberg and Hunt, 1995; Borjas, 1995; Carrington and Lima, 1996; Dustmann et al., 2005; Borjas et al., 2011, 2008; Ottaviano and Peri, 2012; Glitz, 2012), little is known about the possible effects on other working conditions that are known to affect health. This paper studies how the sorting of immigrants across jobs affects their health trajectories, and, in turn, the health of natives and previous immigrant cohorts. Our contribution is twofold. First, we focus on one of the mechanisms affecting immigrants' health convergence by analysing the role of occupations. Secondly, to the best of our knowledge this is the first paper studying the effects of immigration on the health of 
the native population. We argue that differences in the initial endowments and composition of capital (health, human capital, and financial endowments) between immigrant and natives can explain the reallocation of tasks in the population and the positive effects of immigration on health outcomes. Indeed, both the lack of detrimental effects on employment and wages, and the reallocation of working conditions can be explained by the complementarity of tasks in the production function (Peri and Sparber, 2009; D'Amuri and Peri, 2010).

Similarly to Akay et al. (2012), who analyse the effect of immigration on individual wellbeing, we focus on Germany, a country characterised by a large and diverse immigrant population. We exploit the richness of the German Socio-Economic Panel (SOEP) as it allows us to analyse the health trajectories of a representative sample of both natives and immigrants in Germany. The SOEP contains information on self-reported and doctor-assessed health conditions and on a large set of socio-demographic characteristics. In addition, it includes occupational titles that can be used to classify occupations based on the total burden or the physical intensity associated with relative working conditions.

We document that regardless of their arrival cohort, immigrants, upon their arrival, are healthier than are their German-born counterparts, but the health of the immigrants rapidly converges to that of the native population. However, the convergence is heterogeneous across immigrants and occurs more rapidly among male immigrants working in more physically demanding jobs. We show that immigrants are more likely to be employed in blue-collar jobs and to be exposed to work-related health risks for longer periods than their native counterparts.

These facts can be explained by a standard Grossman (1972) health capital model. Ceteris paribus, low-skilled individuals are more willing to accept risky occupations, trading off health for higher lifetime earnings (Case and Deaton, 2005; Grossman, 1972). As immigrants appear to be positively selected on health with respect to their population of origin, but have lower education and less wealth than natives, their incentives to trade-off money for health capital are even greater. Therefore, immigrants may be more willing than natives to accept poorer working conditions for higher wages.

Having determined that immigrants are more likely to work in riskier occupations than natives and that the health deterioration occurs significantly more quickly among immigrants working in physical demanding occupations than among those working in less demanding occupations, we turn to investigate how immigration affects the health trajectories of both natives and immigrants in Germany. Merging the SOEP with local labour market characteristics allows us to analyse how changes in the spatial concentration of immigrants over time affects health in the resident population. One of the major challenges of the spatial correlation approach is that the location of immigrants across different areas might be endogenous. 
Including individual fixed effects allows us to analyse how changes in the individual exposure to immigrants affected his working conditions and health over time. Controlling for local labour market fixed effects and a set of time varying local labour market characteristics, we are able to account for the omitted variable bias associated with permanent local area characteristics or correlated with important time-varying factors (GDP, unemployment, etc.). To further address the issue of endogeneity, we exploit the fact that historical concentrations of immigrants are a good predictor of current immigrant inflows and use the traditional shiftshare instrument (Card, 2001). Conditioning on individual, local area, and year fixed effects, and controlling for time-varying characteristics of the local labour market, we can reasonably assume that past immigrant concentrations are uncorrelated with current unobserved labour demand shocks that may be correlated with health. Our results are robust to alternative model specifications and estimation methods.

We find that a higher immigration rate increases the likelihood of the native population reporting better health outcomes. Effects are larger but less precisely estimated for previous cohorts of immigrants. Consistent with our hypothesis, the positive effects are concentrated among low-skilled men in blue-collar jobs. We find no evidence that immigration has significant effects on the allocation of blue- and white-collar jobs in the population. However, we do observe that immigration reduces the degree of physical intensity, the number of hours worked, and the likelihood of working at night among blue-collar workers. At the same time, consistent with several studies analysed the effects of immigration in Germany (D'Amuri et al., 2010; Bonin, 2005; Pischke and Velling, 1997), we find no evidence of detrimental effects of immigration on wages and employment. ${ }^{1}$ The effects of immigration on these observable working conditions can explain approximately $25 \%$ of the reduced form effect of immigration on health.

The paper is organised as follows. Section 2 presents the data, discusses the healthy immigrant effect and illustrates the role of occupation in affecting the convergence over time. In Section 3, we analyse the effect of immigration on the health of the native population and explore the possible mechanisms behind it. Concluding remarks are reported in Section 4.

\footnotetext{
${ }^{1}$ It is worth noting that while most studies for Germany found no evidence of detrimental effects on wages, recent evidence using establishment-level analysis (Campos-Vazquez, 2008) or a quasi-experimental approach (Glitz, 2012) finds negative short-run effects on employment. Consistent with these studies, we find evidence of negative short-run effects on employment among individuals previously employed in blue-collar occupations.
} 


\section{Data and Stylised Facts}

\section{$2.1 \quad$ Data}

Our main data are drawn from the German Socio-Economic Panel dataset (SOEP). The SOEP is a longitudinal panel dataset that contains information on a rich set of individual socio-economic characteristics. This annual household based study was initiated in 1984 and includes annual information on approximately 12,000 households, and more than 20,000 individuals. Annually, each household member above the age of 16 is asked questions on a broad range of socio-economic indicators.

The panel is unbalanced as some respondents entered the sample after 1984 and others left the sample before 2010. Because the SOEP oversamples immigrants and contains several questions on both health outcomes and job characteristics, it is an ideal source for investigating the relationship between immigration, work conditions and health status of both natives and immigrants. For a detailed description of the survey, see Haisken-DeNew and Frick (2005).

The SOEP provides information on several health metrics (self-assessed health status, satisfaction with health, number of hospital visits, etc.). In this paper, we focus on one main health outcome, a dummy variable equal to one for a doctor-assessed disability (disability). Respondents were asked about their current disability status from 1984 onwards. Furthermore, respondents are also asked about the degree of any disability they have. The question is: "What is the extent of this capability reduction or handicap (in percentages) according to the most recent diagnosis?" We use an indicator for whether individuals reported a disability greater than $30 \%{ }^{2}$ Though self-reported, this variable relies on doctor-assessment, and therefore, it is less subject to heterogeneity in the perception of health. This is particularly relevant for us, as we compare the health of immigrants and natives and self-assessment may vary systematically across ethnicities. Moreover, as we hypothesise that immigration might improve the average working conditions of natives, it is natural to focus on a health metric that is directly affected by work-related injuries. In the Appendix, we evaluate the robustness of our results using subjective health measures, such as self-rated health, which we dichotomise as poor health, and handicaps due to poor health, which refers to any impediment in carrying out day-to-day activities.

In addition, the SOEP includes occupational titles that are coded into the International Standard Classification of Occupations (OECD, ISCO-88) at the 4-digit level. Using the ISCO classification and the General Index for Job Demands in Occupations (Kroll, 2011), we

\footnotetext{
${ }^{2}$ As a robustness check, we consider the sensitivity of our results to different definitions of disability status.
} 
constructed a 1 to 10 metric of the physical intensity (physical burden) associated with a given occupational title. Furthermore, we can classify workers according to major occupations (1digit) and identify blue- and white-collar workers using the standard OECD classifications.

Using the information on the geographical residence of the individual we merged individual-level information with data on local labour market characteristics drawn from the INKAR dataset at the level of German regional policy regions (RORs). These regions are defined based on their economic inter-linkages by the Federal Office for Building and Regional Planning. There are 97 regional policy areas. Our main variable of interest is the percentage of immigrants in the total resident population in a ROR. From the INKAR dataset we also draw information on employment rate, GDP per capita, and gross value added per worker. As this dataset is available only for the period 1996-2010, we restrict the analysis of the effects of immigration (Section 4) to this time period.

We report summary statistics for the main variables used in Table 1. Columns 1-4 report means and standard deviation by immigrant status. We restrict the analysis to individuals aged between 25 and 59 to avoid changes in perceived or actual health after retirement (Mazzonna and Peracchi, 2012). Furthermore, this restriction allows us to ignore changes in the legal retirement age over the years considered in the sample. When considering the unconditional mean differences, there appears no evidence of a healthy immigrant effect for men. In fact, there are only slight and not significant differences in health status between Germans and immigrants. However, there are large socio-economic differences between the two populations. With respect to our sample, immigrants are less educated and have lower wages. Furthermore, they are more than twice as likely as Germans to work in blue-collar occupations and on average work 2.6 years more in these occupations in our sample. We divide immigrants into three main cohorts of arrival: $60 \%$ of the immigrants arrived before the 80 s, with the remaining $40 \%$ almost equally divided between the 80 s and the period following the fall of the Berlin wall in 1989. ${ }^{3}$ Among immigrants in the sample, the average number of years spent in Germany in the sample is 18 years.

Panel B shows that with respect to women the incidence of doctor-assessed disability is significantly less among immigrants than among their native counterparts. In the next

\footnotetext{
${ }^{3}$ Preliminary analysis conducted to identify the most important waves of immigration in Germany indicate that that these waves are also strongly connected with the most important nationality groups present in the data (see Table A.2, in the Appendix). In particular, the first wave of migration considered, immigrant arriving before the ' $80 \mathrm{~s}$, is composed mainly by immigrants from Turkey, ex-Yugoslavia and other Mediterranean countries (Italy, Greece and Spain). The first-wave of immigrants is comprised primarily of low-skilled employed in blue-collar occupations. The second and third waves, however, are more heterogeneous as the largest share of immigrants came from Eastern Europe and Russia. On average, the more recent immigrants show higher educational attainment. However, despite the higher levels of human capital, recent immigrants are not significantly different from previous cohorts in their likelihood of working in physical demanding jobs, which is significantly higher than that of their native counterparts.
} 
section, analysing the health trajectories of immigrants over time, we show that among immigrant men have a greater health advantage than immigrant women upon arrival, but their health converges to that of their native counterparts at a faster pace. This is particularly true when we focus on doctor-assessed disability and it is consistent with the fact that women are less likely to be employed in strenuous jobs. As shown in Table 1, men are much more likely to be employed in blue-collars jobs ( $80 \%$ vs. $40 \%)$ and in occupations characterised by a greater physical burden (7.6 for men vs. 6.6 for women). Furthermore, we find the same descriptive statistics for the sample used in Section 4, which restricts the analysis to 1996 onward.

\subsection{Stylised Facts: Immigrant Health and Working Conditions}

Figure 1 illustrates the health trajectories of immigrants over time spent in Germany. We focus on a balanced panel of individuals aged between 25 and 34 years old in the second wave of the survey (1985) — which includes the first immigrant subsample - to observe individual over a sufficiently long span of time and to avoid selection concerns related to attrition and early retirement. With respect to immigrants, we exclude those who had been in Germany for more than 10 years as of 1985, as we are interested in analysing the health trajectories following migration. To retain a sufficient number of observations, we pool immigrants with less than 10 years in Germany.

Immigrants, both men and women, are found to be healthier upon arrival with a lower incidence of doctor-assessed disability than the one observed among natives. While this initial health advantage might be partially explained by the fact that upon arrival immigrants are less likely to visit a German doctor and therefore are less likely to report it, we find a similar result when considering perceived health status. However, over time the average incidence of doctor-assessed disability grows significantly faster among immigrant men than among natives. Interestingly, we do not observe convergence among women. As previously mentioned, the literature on the healthy immigrant effect has largely focused on selectivity, behavioural assimilation, return migration, and access to care (Antecol and Bedard, 2006). However, the differences observed in the health trajectories of immigrant men and women suggest that mechanisms other than differences in access to care, may explain the unhealthy convergence observed among immigrant men. While we acknowledge that assimilation in behaviours (dietary and substance use) are important mechanisms underlying the health trajectories of immigrants over time, in this paper we focus on the role of working conditions in the host country, a factor that has been largely neglected in the literature. Though recent studies have shown evidence that working in physically demanding occupations has negative 
effects on health (Ravesteijn et al., 2013; Case and Deaton, 2005; Fletcher et al., 2011) ${ }^{4}$. Having already shown in Table 1 that immigrant men are more likely than native men to work in occupations that involve higher physical intensity ${ }^{5}$, it is natural to ask whether the rapid convergence in their health is heterogeneous across occupational groups. Indeed, Figure 2 shows that the deterioration of immigrant health is driven by those individuals working in high physically demanding occupations.

Table 2 provides more evidence on these health trajectories by analysing health differences between immigrant and native men using standard linear panel data models. In particular, similarly to Antecol and Bedard (2006), we estimate equations of the following form:

$$
h_{i t}=\alpha_{i}+\beta X_{i t}^{\prime}+\gamma C_{i}^{\prime}+\lambda Y S M_{i t}+\theta_{t}+\epsilon_{i t}
$$

where $h_{i t}$ denotes the health of individual $i$ at time $t ; \alpha_{i}$, is an individual fixed effect; $X_{i t}^{\prime}$ are a set of individual time varying characteristics (a quadratic control in age, an indicator for marital status, dummies for three educational groups); $C_{i}^{\prime}$ denotes a vector of dummy variables identifying immigrants arrival cohorts (Germans are taken as baseline); $Y S M_{i t}$ is a quadratic control in years since migration (YSM) that we include to analyse the health trajectories of immigrants with time spent in Germany. Moreover, we include survey years fixed effects, $\theta_{t}$, and a full set of regional fixed effects at the NUTS2 level. ${ }^{6}$ Column 1 reports the results from quasi-fixed effect model (QFE). This model imposes a restricted correlation between the individual fixed effect $\alpha_{i}$ and our time varying regressors, $X_{i t}^{\prime}$ (Mundlak, 1978), which allows us to evaluate the effect of the time-invariant individual characteristics (e.g., immigrant cohort). In columns 2 we use individual fixed effects (FE). Standard errors are clustered at the individual level. Given the discrete nature of our dependent variable, we evaluate the robustness of our results using non-linear panel data methods such as a random effect probit model. ${ }^{7}$

Regardless of their arrival cohort immigrants, upon their arrival, are found to be healthier than their German-born counterparts once we control for socio-demographic characteristics and YSM. In particular, immigrant men, upon their arrival, have a much lower incidence of

\footnotetext{
${ }^{4}$ We find similar evidence in our sample. In particular, we find that one additional year spent in a physically demanding occupation is associated with an increase of $3 \%$ in the incidence of disability. Results are available upon request.

${ }^{5}$ Further evidence is provided in Table A.3. See also Section 3.4.

${ }^{6}$ The Nomenclature of Territorial Units for Statistics (NUTS) is a geocode standard developed and regulated by the European Union. NUTS2 is the lowest level of geographical detail available for the entire period of the SOEP data (1984-2010). Note that while we do have information on regional policy regions (ROR), these regions were redefined in 1996 and, therefore, can only be used for pre/post 1996 analysis, thus ignoring the readjustment of ROR (Knies and Spiess, 2007).

${ }^{7}$ Result -available upon request- are very similar to those reported in this section.
} 
doctor-assessed disability than natives (-0.06, see column 1), but their health quite rapidly converge to natives' health, in approximately 15 years (see the coefficient on YSM). Consistently with Figure 2, columns 3 and 4 show that the yearly rate of health depreciation associated with time spent in Germany (YSM) is significantly lower among men who, in the previous year, were employed in low physical burden jobs (jobs with physical intensity lower than the median). These results are robust to the inclusion of controls for German language skills and to the restriction of the analysis to the sample of immigrants.

In Table A.1 we report the same analysis for women and show that conditioning on standard socio-demographic controls, the health advantage upon arrival is relatively less among women (see column 1). Health selectivity at the time of migration appears to be less important among female immigrants than among male immigrants. ${ }^{8}$ Interestingly, the coefficient on the interaction between the level of physical burden and time spent in Germany has no significant effects among women. Again, employed women are a highly selected sample and, even when employed in blue-collar jobs, they are likely to work in less physically demanding occupations than their male counterparts (see Table 1).

Overall, the analysis of the role of occupation suggests that immigrants are more likely than natives to work in physically demanding jobs and that the health convergence occurs more rapidly among immigrants working in blue-collar jobs. These facts motivate us to analyse whether immigration may affect natives' health by changing the allocation of working conditions in the population.

\section{$3 \quad$ Effects of Immigration on Health}

Figure 3 depicts a strong negative association between immigration and the average physical burden of a man's job at the ROR level. We use a lagged value of the immigration rate because it is difficult to believe that immigration has an immediate effect on natives' health, in particular when we consider a disability status that must be assessed by a doctor. In Figure 4, we observe only a slightly negative relationship between the share of men reporting a disability in a ROR and men's immigration rate in the previous year (the coefficient on immigration is very small but significant at the $5 \%$ level). These associations are consistent with our conjecture that immigration, by increasing the supply of workers willing to tradeoff health for increased lifetime earnings, may induce a reallocation of tasks in the resident population and, in turn, have positive spillovers on their physical health status.

\footnotetext{
${ }^{8}$ To assess this hypothesis we examined separately single vs married women and found significant differences between the two groups. In particular, there was no evidence of a health advantage when considering married women who are more likely to have migrated for family rather than economic reasons and, therefore, less selected.
} 


\subsection{Empirical Specification}

To identify the effect of immigration on the health of the resident population, we exploit variation over time in the share of immigrants living in a ROR between 1996 and 2010. In our baseline specification we model health according to the following static linear model:

$$
h_{i r t}^{*}=\alpha_{i}+\beta I R_{r t-1}+X_{i r t}^{\prime} \gamma+Z_{r t}^{\prime} \lambda+\delta_{r}+\theta_{t}+\epsilon_{i r t},
$$

where $h_{i r t}^{*}$ is the latent health status of individual $i$ at time $t$ in ROR $r ; \alpha_{i}$ is a timeinvariant individual fixed effect; $I R_{r t-1}$ is the immigration rate in $\mathrm{ROR} r$ in the previous year; $X$ is a vector of time varying individual characteristics (such as age, education, marital status and number of children); $Z_{r t}^{\prime}$ is a vector of time-varying labour market and economic conditions; $\delta_{r}$ and $\theta_{t}$ are ROR and years fixed effects, respectively; and $\epsilon_{i r t}$ captures the residual variation in health status. The preferred estimation method for this model is the FE estimator as it allows the unobserved time-invariant individual heterogeneity $\alpha_{i}$ and our regressors to be correlated. Unfortunately, $h_{i r t}^{*}$ is not directly observed. Instead, we observe some health binary indicators $\left(h_{i r t}\right)$, such as disability status or self reported poor health, with an observation mechanism that can be expressed as:

$$
H_{\text {irt }}=\mathbb{1}\left\{h_{\text {irt }}^{*}>0\right\} .
$$

For this reason, a straightforward choice would be the use of non linear models, such as a probit or logit model. However, with these models we cannot rule out the individual effect, $\alpha_{i}$ when using within transformation nor can we directly estimate it because of the well-known incidental parameters problem. As we are interested in estimating the average effect of immigration on the population, the linear probability model might represent a good approximation of this effect (Angrist and Pischke, 2008). However, for robustness, we estimate equation (2) using a correlated random effect probit estimator, allowing a restricted dependence between $\alpha_{i}$ and the regressors in $X_{i r t}^{\prime}$ (Wooldridge, 2002). In practice, we use a random-effects model augmented with means of time-variant individual characteristics. We are instead less concerned that the disability status may be an absorbing state which would bring into question the validity of the fixed effect estimator. Having chosen a relatively low threshold to define disability (30\%), we actually observe that approximately one-third of the changes in disability status occur among people who reported disability in the previous year and are no longer assessed with a disability greater than $30 \%$.

Another relevant concern is that there might be confounding factors that are correlated with the distribution of immigrants across RORs and individual health. In particular, one 
could argue that the large number of controls for market and economic condition at the ROR level may not be sufficient to account for all time-varying unobservables that could confound the relationship between immigration rate and health. We contend that the extensive set of observable individual characteristics, the ROR fixed effects and the ROR time-varying controls capture most of the potentially omitted variables. If anything, we posit that pull factors that attract more immigration, such as the economic conditions of the RORs, should lead to a downward bias of the effect of interest, given the well-known negative (short-run) correlation between the economic cycle and health (Ruhm, 2000). However, to further address these concerns, we include ROR specific time trends and use an instrumental variables approach. Following Card (2001), we use an instrumental variable based on a "shift-share" of national levels of immigration into RORs. In practice, we exploit the fact that immigrants tend to locate in areas with a higher density of immigrants from their own country and we distribute the annual national inflow of immigrants from a given source country using the 1996 distribution of immigrants from a given country of origin across RORs. ${ }^{9}$ Using the distribution of immigrants as of 1996, we reduce the risk of endogeneity due to the fact that annual immigration inflows across RORs might be driven by time-varying characteristics of the ROR associated with health outcomes. One potential threat to the validity of this instrument is that if local economic shocks that attracted immigrants persisted over time, the instrument cannot credibly address the endogeneity problem. However, including individual, ROR, and year fixed effects and controlling for time-varying characteristics of the local labour market, we believe that this problem is substantially mitigated, and that we can reasonably assume that past immigrant concentrations are uncorrelated with current unobserved labour demand shocks that might be correlated with health.

Finally, we assess the robustness of our findings to different assumptions about the timing of the effect of immigration on health. As previously mentioned herein, there in no reason to conclude that immigration should have direct and immediate effects on residents' health, particularly if we consider that immigration affects health through its impact on the labour market. Therefore, we used lagged values of the immigration rate to predict its effects on health. To not lose too many observations, we show results using only immigration rate at time $t-1$. However, as a robustness check, we consider past values for the immigration rate up to $t-3$. Moreover, we implement placebo tests on forward value of the immigration rate (up to $t+1)$ (see Table A.2 in the Appendix).

\footnotetext{
${ }^{9}$ Note that the classification of RORs changed in 1996 and therefore we cannot use earlier years as a base to construct our shift-share instrument.
} 


\section{$3.2 \quad$ Results}

Table 3 illustrates the effect of immigration on doctor-assessed disability for men (Panel A) and women (Panel B). In each panel, we report the effect of the total immigration rate and that of the gender-specific immigration rates (separated estimates). Given the result reported in Section 3, gender specific immigration rates may better proxy for the actual exposure to immigrants in the labour market.

As presented in Section 3.1, we estimate this model using individual fixed effects and a two stage least squares model (2SLS) using the Card (2001) instrument. Column 1 controls for a set of individual socio-demographic controls (a quadratic in age, gender, a dummy for East Germany, education, marital status, the logarithm of household size), ROR fixed effects, survey year fixed effects, and a set of time-varying characteristics at the ROR level (gross value added, GDP per capita, employment rate, and the logarithm of total population). In column 2, we include ROR-specific time trends. The 2SLS estimates are reported in column 3.

Panel A shows that immigration is negatively associated with likelihood of men reporting a doctor-assessed disability. As expected the coefficient is larger when using the genderspecific immigration rate. The 2 SLS estimate confirms that immigration reduces the likelihood of reporting a doctor-assessed disability. A one standard deviation increase in the immigration rate (2.35 percentage points) reduces the risk of a doctor-assessed disability by approximately $16 \%$, with respect to the mean. As expected, the 2SLS point estimates are larger (see the discussion in Section 3.1).

On the contrary, we do not find significant effects among women (Panel B). This finding can be explained by the fact that women are less likely to be employed in blue-collar jobs and, more generally, in physical demanding jobs. If we believe that the mechanism behind the effect of immigration on health is the change in the average working conditions, it is not surprising to find no effects among women as they are significantly less likely than men to work in strenuous occupations.

Having assessed the presence of a significant negative effect of immigration rate on the likelihood of men reporting a disability, in Table 4, we explore the heterogeneity of the effect of men's immigration rate by foreign born status (Panel A), education (Panel B), and occupational type (Panel C). We report results from both FE and 2SLS. The effects are significantly greater among individuals who are more likely to work in physically demanding jobs, namely previous cohorts of immigrants and low-skilled individuals. Among immigrants, the 2SLS coefficient is less precisely estimated, but the point estimate is substantially unchanged. For the native population, the effects are relatively smaller than those found in the whole resident population. Interestingly, Panel B shows that the effect is concentrated 
among people without a college education, while for college graduate the estimated effect is small and not statically different from zero. Similarly, Panel C shows that the effect of immigration on health is largely driven by blue-collar workers. This result is consistent with our hypothesis that immigration may induce a reallocation of tasks and working conditions and that individuals who are in jobs associated with a higher risk of negative health effects benefit the most from an increase in the supply of low-skilled and relatively healthy immigrants.

Consistent with previous analysis, we do not find evidence of significant effects on women. ${ }^{10}$

\subsection{Possible Mechanisms}

To shed further light on the potential mechanism underlying our reduced-form results on the effects of immigration on health, we turn to analyse the effects of immigration on the labour market. In Table 5, we analyse whether immigration affects the likelihood of individuals of being employed in occupations involving different levels of physical burden.

To conserve space, we report only results from the FE estimate; however the 2SLS estimates are consistent with those reported in the Table 5. Column 1 shows no effect of immigration on the likelihood of working in blue-collar occupations. In column 2, we consider a more precise measure of the physical intensity associated with a given occupation. Again, we do not find evidence of significant effects on physical burden. However, column 3 shows that immigration significantly reduces the average physical burden of people previously employed in blue-collar occupations. A one standard deviation increase in immigration decreases by $4 \%$ the average physical burden. ${ }^{11}$ As the estimated effect is rather small, it only partially accounts for the positive effect of immigration on health. This suggests that the reallocation of tasks and jobs may occur within similar occupations, rather than across macro categories. In other words, we do not observe dramatic shifts from white to bluecollar jobs. However, we do have some evidence that among blue-collar workers an increase in the immigration rate in the ROR is associated with a reduction in the average physical burden. Unfortunately, we do not observe task changes within the same job over time, but only changes in the physical burden associated with job changes. If as suggested by column 3 , most of the effect of immigration on workers' physical burden occurs across similar occupations, it is reasonable to expect larger effects on the reallocation of tasks within a given occupational category. Therefore, our estimate is likely to capture a lower bound of the total

\footnotetext{
${ }^{10}$ The results are available upon request.

${ }^{11}$ Consistent with our previous results, we find no evidence of significant effects for women. Results are available upon request.
} 
effect of immigration on workers' physical burden. We test this conjecture using information regarding the perceived strenuousness of the occupation. Information on perceived physical intensity is acquired only in the 2001 survey. Columns 4 and 5 replicate the results presented in columns 2 and 3 with respect to perceived physical burden. As we only have information for one year, we must exploit cross-sectional variation across RORs to identify the effects of immigration. For this reason, we use a simple OLS regression including area fixed effects at the level of NUTS-1. ${ }^{12}$ The results suggest that immigration is associated with a reduction in the perceived physical burden. A one standard deviation increase in the immigration rate is associated with a $25 \%$ reduction in perceived physical burden. Furthermore, and consistent with our prior, column 6 indicates that the coefficient is robust to the inclusion of a full set of dummies for each value of the physical burden of the occupation derived from the dependent variable in column 2 and 3. Again, these results suggest that our objective measure of physical burden captures only a small part of the total effect of immigration on workers' physical burden.

In Table 6, we analyse the effects of immigration on a broad set of labour market outcomes and working conditions. ${ }^{13}$ Columns 1 and 2 confirm previous studies finding no evidence of negative effects on employment and wages. If anything, and consistent with D'Amuri et al. (2010), our estimates suggest positive and slightly significant effects on wages. Even more interestingly, an increase in the immigration rate significantly reduces the number of working hours (column 3), the likelihood of working overtime (column 4), and the likelihood of working nightly shifts (column 5). The effect on nightly shifts, however, is not precisely estimated as this information is available only in a few waves of the survey. However, the estimate is significant when using quasi-fixed effects (coef. -0.015**; std.err.: 0.006). ${ }^{14}$

Overall, these results suggest that a part of the positive effect of immigration on health is explained by the reduction in the average working load, better schedules, and no detrimental effect on the wages. Column 6 shows that immigration is also significantly associated with a reduction in the share of individuals reporting that they are concerned about their health status. Including in our baseline specification (Table 5, column 1) controls for income, employment status, working hours, indicators for whether individuals work overtime hours or engage in nightly shifts, and indicators for the average physical burden associated

\footnotetext{
${ }^{12}$ The coefficients are substantially unchanged, though less precisely estimated, when using NUTS-2 fixed effects.

${ }^{13}$ For space considerations, we do not report the 2SLS estimates. However, the results are largely consistent with the estimates presented in Table 6.

${ }^{14}$ The quasi-fixed effect estimates controls for the individual average age, education, marital status, employment status and household size. Using quasi-fixed effects, we find also find a negative effect of immigration on the likelihood of working evening shifts, working on Sundays, and on the perceived risk of work accidents.
} 
with the occupation reduces the effect of immigration on the doctor-assessed disability by approximately 25\% (coef. -.0034; std.err. 0.0015 ).

\subsection{Robustness Checks}

In Table 1, we report evidence of large unconditional differences between immigrants and natives regarding the probability of working in physically demanding jobs. In Table A.3, we use a probit model to better analyse such differences. In particular, being an immigrant is associated with an increase in the index of the physical intensity of the job, which ranges between $20 \%$ and $30 \%$ (with respect to the mean) depending on the cohort considered. While these differences are observed among both men and women, it is the reference category among the native workers (see the constant terms) and the fact that these regressions are conditional on being employed that change. Both the employment rate and the average number of hours worked are significantly lower among immigrant women (only 50\% are employed), thus leading to a highly selected sample.

As mentioned in Section 4.1, we replicate the estimates reported in Table 5 using the immigration rate at different points in time (both past and forward values). As a placebo test, we also estimate the effect of immigration rate at time $t+1$, which should not affect respondents' health at time $t$. Table A.4 shows the results of this analysis. As expected the forward value of immigration rate does not affect respondents' health, while the contemporaneous effect is not statistically significant. Using lagged values of the immigration rate (up to $t-3$ ), we instead confirm the main finding of a positive effect of immigration on individual health. The direction of the effect of immigration on health is confirmed when using more subjective health outcomes, such as health limitations ${ }^{15}$ and self-assessed health status (see Table A.5). Note that though the fixed effect estimate is not precise, the 2SLS estimates are larger and marginally significant. In addition, we confirm the robustness of our main results to different definitions of disability status. As mentioned in the data section, individuals are asked to report whether they were registered as having a reduced capacity for work or as being severely disabled, and if so, what is the degree of their disability. Following previous studies (see, for instance, Oswald and Powdthavee (2008)), we adopted the threshold of $30 \%$ to define disability status. However, our results are robust to changes of the threshold between $10 \%$ and 50\%. Interestingly, while the benefits associated with different levels of disability differ significantly (Burkhauser and Schroeder, 2007; Boersch-Supan and Juerges, 2011), the impact of immigration on the likelihood of doctor-assessed disability among the native population is always negative and the magnitude of the effect does not

\footnotetext{
${ }^{15}$ The indicator for health limitations is used only as a robustness check for the Section 2.2 as this variable is not available in all survey years.
} 
change substantially. This is reassuring as one may be concerned that the differences in the likelihood of reporting a given percentage of disability are driven by the benefits associated with specific thresholds. ${ }^{16}$

Given the binary nature of our main outcome variable, doctor-assessed disability, we replicate our main results using a correlated random effect probit that includes the individual mean over time of some socio-demographic characteristics in the model. For computational reasons, we substitute the ROR fixed effect with a full set of NUTS2 fixed effect (52 regions). Table A.6 reports the average partial effect (APE, see Wooldridge 2005).

Results are very similar to those estimated using linear FE (and smaller than the 2SLS). Again, we find larger effects among immigrants and low skilled. ${ }^{17}$

\section{Conclusion}

This paper contributes to previous studies on the effects of immigration by analysing the impact of immigration on the health of immigrants and native workers. First, we document the importance of occupations and physical burden when explaining the health trajectories of immigrants. We show that the convergence in health is heterogeneous across immigrants and, in particular, it occurs more quickly among those working in more physically demanding jobs. Immigrants are significantly more likely to work in this type of jobs and to be exposed to jobrelated health risks for longer periods. Secondly, we investigate whether the shock to labour supply induced by immigration affects health outcomes by changing the allocation of tasks and working conditions in the resident population. In particular, we find that immigration reduces the likelihood of doctor-assessed disability. The effects are mostly concentrated on low-skilled individuals and larger on previous cohorts of immigrants.

Our results suggest that immigration improves working conditions for native workers by reducing the average number of hours worked, the physical intensity of blue-collar jobs, and the likelihood of working nightly shifts. At the same time, we find no evidence of negative effects on employment and wages, and find positive effects on health expectations. Overall, the improvement observed in these working conditions contributes to explain the reduced form effect on health. We argue that these results are consistent with the Grossman (1972) health capital model. Furthermore, differences in the initial endowments and composition of capital (health, human, and financial endowments) between immigrant and their native

\footnotetext{
${ }^{16}$ Results are available upon request.

${ }^{17}$ As an additional robustness check, we run group-level estimates at the ROR-year level. This approach allows us to transform our dependent variable in a continuous variable that measures the incidence of disability in a specific ROR at time $t$. The results, available upon request, are consistent with those reported thus far, with large and significant effects when among low-skilled workers.
} 
counterparts can explain the reallocation of tasks in the population. The complementarity of tasks in the production function account both for the lack of detrimental effects on employment and wages, and the reallocation of natives and previous immigrants in jobs involving better working conditions. These labour market effects explain, to some degree, the positive effects of immigration on health outcomes. In particular, we show that the effects of immigration on observable working conditions explain approximately $25 \%$ of the reduced form effect of immigration on health.

The evidence presented suggests that policy-makers should not neglect the positive effects of immigration on native working conditions and health. At the same time, as newly arrived and healthy immigrants might not be aware of the health risks associated with particular working conditions, granting information and access to care to those immigrants at higher risk could contain the process of unhealthy assimilation and the associated costs for the health care system. 


\section{References}

Akay, A., Constant, A. F., Giulietti, C., 2012. The impact of immigration on the well-being of natives. IZA Discussion Paper 6630.

Angrist, J. D., Pischke, J.-S., 2008. Mostly Harmless Econometrics: An empiricist's companion. Princeton University Press, Princeton, NJ.

Antecol, H., Bedard, K., May 2006. Unhealthy assimilation: Why do immigrants converge to American health status levels? Demography 43 (2), 337-360.

Boersch-Supan, A. H., Juerges, H., 2011. Disability, pension reform and early retirement in Germany. NBER Working Paper 17079.

Bonin, H., 2005. Wage and employment effects of immigration to germany: Evidence from a skill group approach. IZA Discussion Paper 1875.

Borjas, G. J., 1995. The economic benefits from immigration. Journal of Economic Perspectives $9(2), 3-22$.

Borjas, G. J., Grogger, J., Hanson, G. H., March 2008. Imperfect substitution between immigrants and natives: A reappraisal. NBER Working Paper (13887).

Borjas, G. J., Grogger, J., Hanson, G. H., September 2011. Substitution between immigrants, natives, and skill groups. NBER Working Paper (17461).

Burkhauser, R., Schroeder, M., 2007. Comparing economic outcomes of populations with disabilities-a method for comparing the economic outcomes of the working-age population with disabilities in Germany and United States. Schmollers Jahrbuch: Journal of Applied Social Science Studies/Zeitschrift für Wirtschafts-und Sozialwissenschaften 127 (2), 227258.

Campos-Vazquez, R. M., 2008. The substitutability of immigrant and native labor: Evidence at the establishment level. Unpublished manuscript, Department of Economics, University of California, Berkeley.

Card, D., 1990. The impact of the Mariel boatlift on the Miami labor market. Industrial and Labor Relations Review 43 (2), 245-257.

Card, D., 2001. Immigrant inflows, native outflows, and the local labor market impacts of higher immigration. Journal of Labor Economics 19 (1), 22-64. 
Carrington, W. J., Lima, P., 1996. The impact of 1970s repatriates from Africa on the Portuguese labor market. Industrial and Labor Relations Review 42 (9), 330-347.

Case, A., Deaton, A., 2005. Analyses in the economics of aging. NBER Chapters (7588), $185-212$.

Chiswick, B. R., Lee, Y. L., Miller, P. W., October 2008. Immigrant selection system and immigrant health. Contemporary Economic Policy 26 (4), 1074-3529.

D'Amuri, F., Ottaviano, G. I., Peri, G., 2010. The labor market impact of immigration in Western Germany in the 1990s. European Economic Review 54 (4), 550-570.

D'Amuri, F., Peri, G., 2010. Immigration and occupation in Europe. Centro Studi Luca d'Agliano Development Studies Working Paper (302).

Dustmann, C., Fabbri, F., Preston, I., 2005. The impact of immigration on the British labour market. The Economic Journal 115 (507), F324-F341.

Fletcher, J., Sindelar, J., 2009. Estimating causal effects of early occupational choice on later health: Evidence using the psid. NBER Working Paper 15256.

Fletcher, J., Sindelar, J., S., Y., 2011. Cumulative effects of job characteristics on health. Health Economics 20 (5), 553-570.

Friedberg, R., Hunt, J., 1995. The impact of immigrants on host country wages, employment and growth. Journal of Economic Perspectives 9 (2), 23-44.

Giuntella, O., 2012. Do immigrants squeeze natives out of bad schedules? Evidence from italy. IZA Journal of Migration 1 (7).

Giuntella, O., 2013. Why does the health of immigrants deteriorate? Evidence from birth records. IZA Discussion Paper 7588.

Glitz, A., 2012. The labor market impact of immigration: A quasi-experiment exploiting immigrant location rules in Germany. Journal of Labor Economics 30 (1), 175-213.

Goldman, D. P., Smith, J. P., Sood, N., 2006. Immigrants and the cost of medical care. Health Affairs 25 (6), 1700-1711.

Grossman, M., 1972. On the concept of health capital and demand for health. Journal of Political Economy 80 (2), 223-255. 
Haisken-DeNew, J. P., Frick, J. R., 2005. Desktop Companion to the German Socio-Economic Panel (SOEP). DIW, Berlin, Germany.

Hunt, J., 1992. The impact of the 1962 repatriates from Algeria on the French labor market. Industrial and Labor Relations Review 45 (3), 556-572.

Jasso, G., Massey, D. S., Rosenzweig, M. R., Smith, J. P., 2004. Immigrant health: Selectivity and acculturation. The Institute for Fiscal Studies Working Paper 4 (23), 1-46.

Kennedy, S., McDonald, J. T., Biddle, N., Dec. 2006. The healthy immigrant effect and immigrant selection: Evidence from four countries. Social and Economic Dimensions of an Aging Population Research Papers 164, McMaster University.

URL http://ideas.repec.org/p/mcm/sedapp/164.html

Knies, G., Spiess, C. K., 2007. Regional data in the German Socio-economic Panel Study (SOEP). DIW Data Documentation 17.

Kroll, L. E., 2011. Construction and validation of a general index for job demands in occupations based on ISCO-88 and KldB-92. Methoden Daten Analysen 5 (63-90).

Mazzonna, F., Peracchi, F., 2012. Ageing, cognitive abilities and retirement. European Economic Review 56 (4), 691-710.

Mundlak, Y., 1978. On the pooling of time series and cross-section data. Econometrica 46, $69-85$.

Orrenius, P. M., Zavodny, M., 2009. Do immigrants work in riskier jobs? Demography 46 (3), $531-551$.

Orrenius, P. M., Zavodny, M., 2012. Immigrants in risky occupations. IZA Discussion Paper 6693.

Oswald, A. J., Powdthavee, N., 2008. Does happiness adapt? A longitudinal study of disability with implications for economists and judges. Journal of public economics 92 (5), 1061-1077.

Ottaviano, G. I. P., Peri, G., 2012. Rethinking the effects of immigration on wages. Journal of the European Economic Association 10 (1), 152-197.

Peri, G., Sparber, C., July 2009. Task specialization, immigration, and wages. American Economic Journal: Applied Economics 1 (3), pp. 135-169. 
Pischke, J.-S., Velling, J., 1997. Employment effects of immigration to germany: an analysis based on local labor markets. Review of Economics and Statistics 79 (4), 594-604.

Ravesteijn, B., van Kippersluis, J., Doorslaer, E., 2013. The wear and tear on health: what is the role of occupation? Tech. rep., Tinbergen Institute Discussion Paper Series.

Ruhm, C. J., 2000. Are recessions good for your health? The Quarterly Journal of Economics 115 (2), 617-650.

Wooldridge, M., 2002. Econometric Analysis of Cross Section and Panel Data. The MIT Press, Cambridge, MA. 
Figure 1: Health Trajectories by Foreign Status and Gender

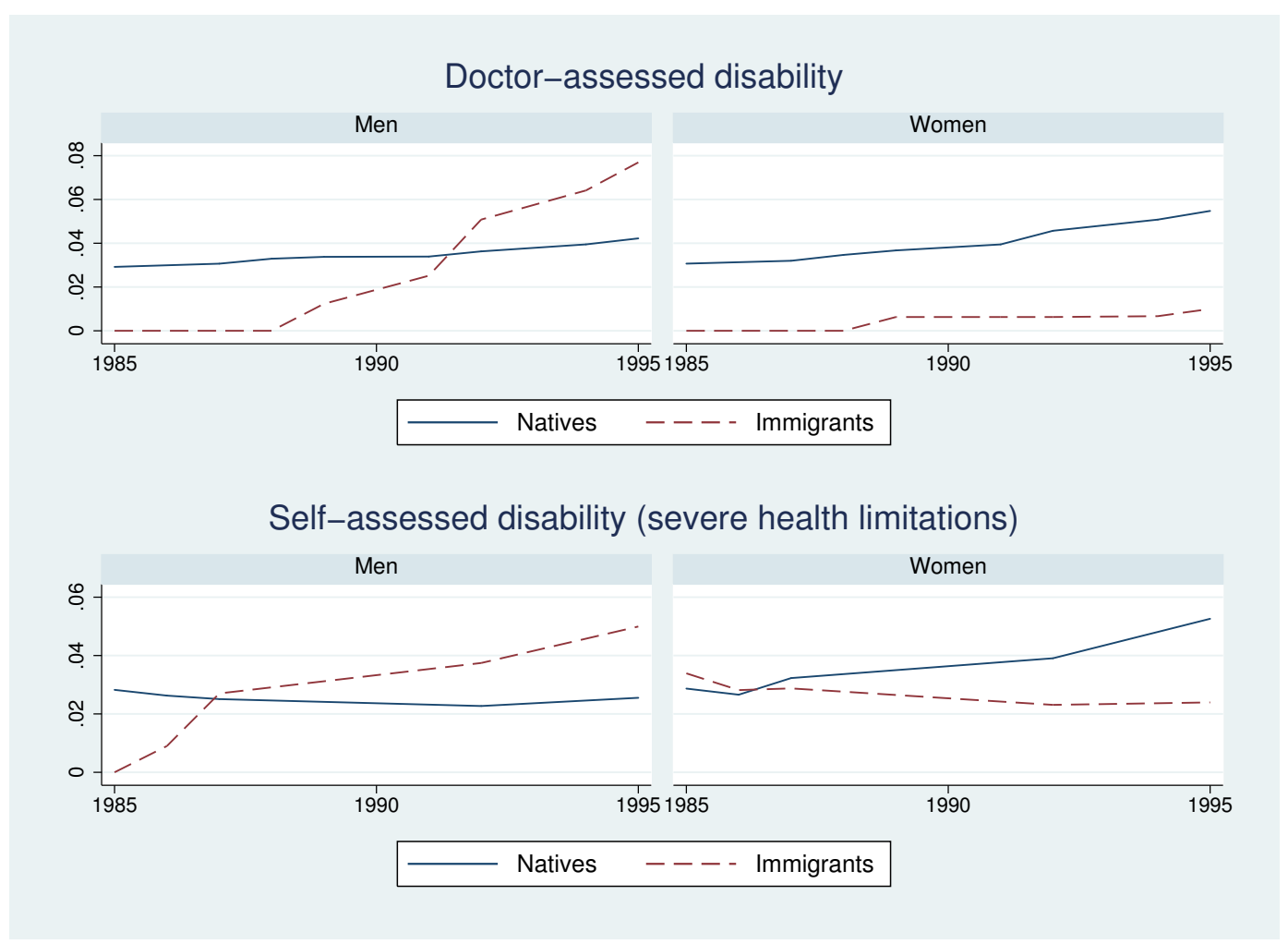

Notes - Data are drawn from the SOEP (1984-2010). We consider a balanced panel of individuals aged between 25 and 34 years old in 1985. We exclude immigrants who had been in Germany for more than 10 years as of 1985 . 


\section{Figure 2: Health Trajectories by Foreign Status and Physical Burden}

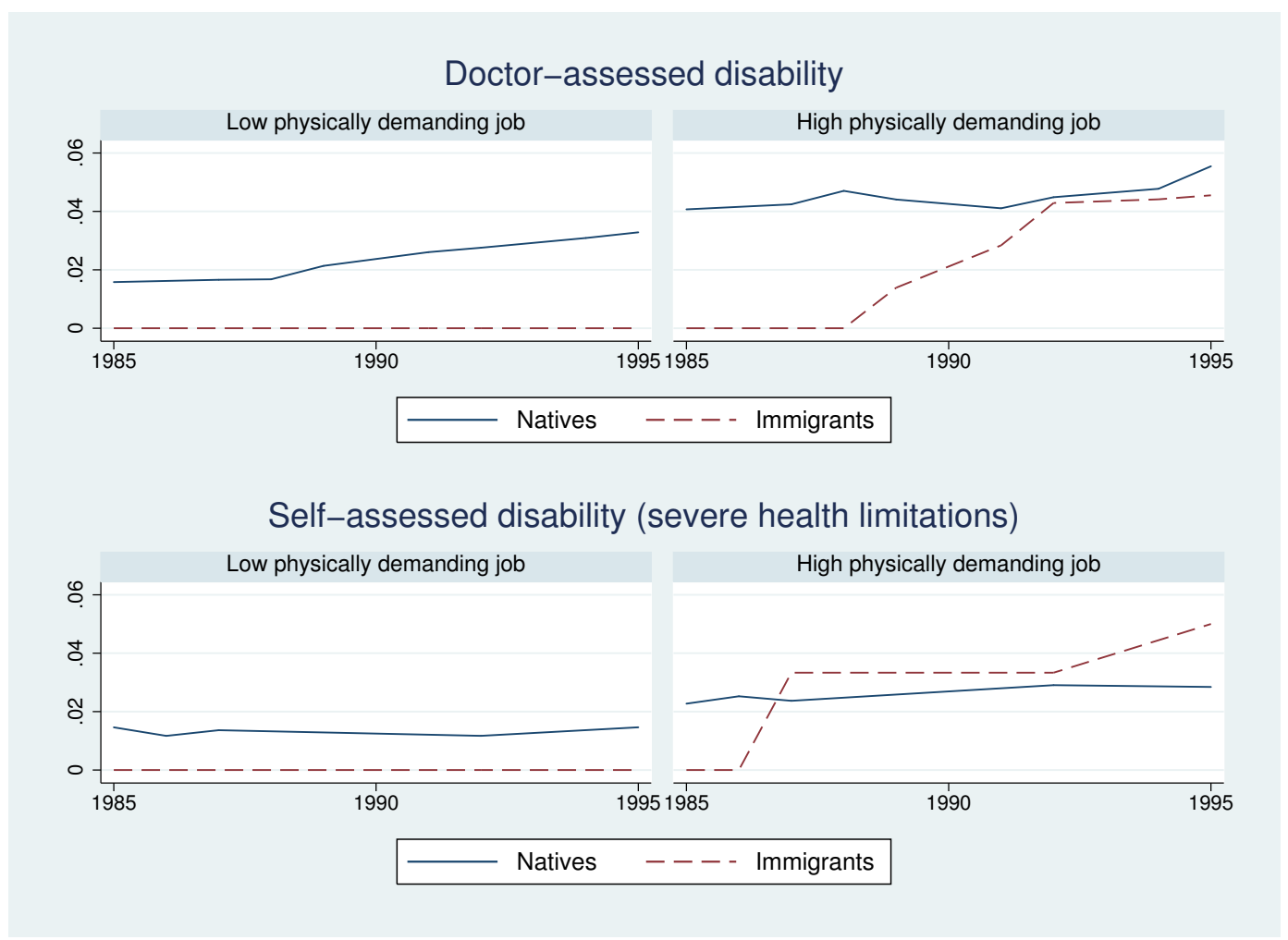

Notes - Data are drawn from the SOEP (1984-2010). We consider a balanced panel of individuals aged between 25 and 34 years old in 1985. We exclude immigrants who had been in Germany for more than 10 years as of 1985. Occupations with an index of physical burden above (below) the median are classified as high (low) physically demanding jobs. 
Figure 3: Immigration and Physical Burden Across German RORs

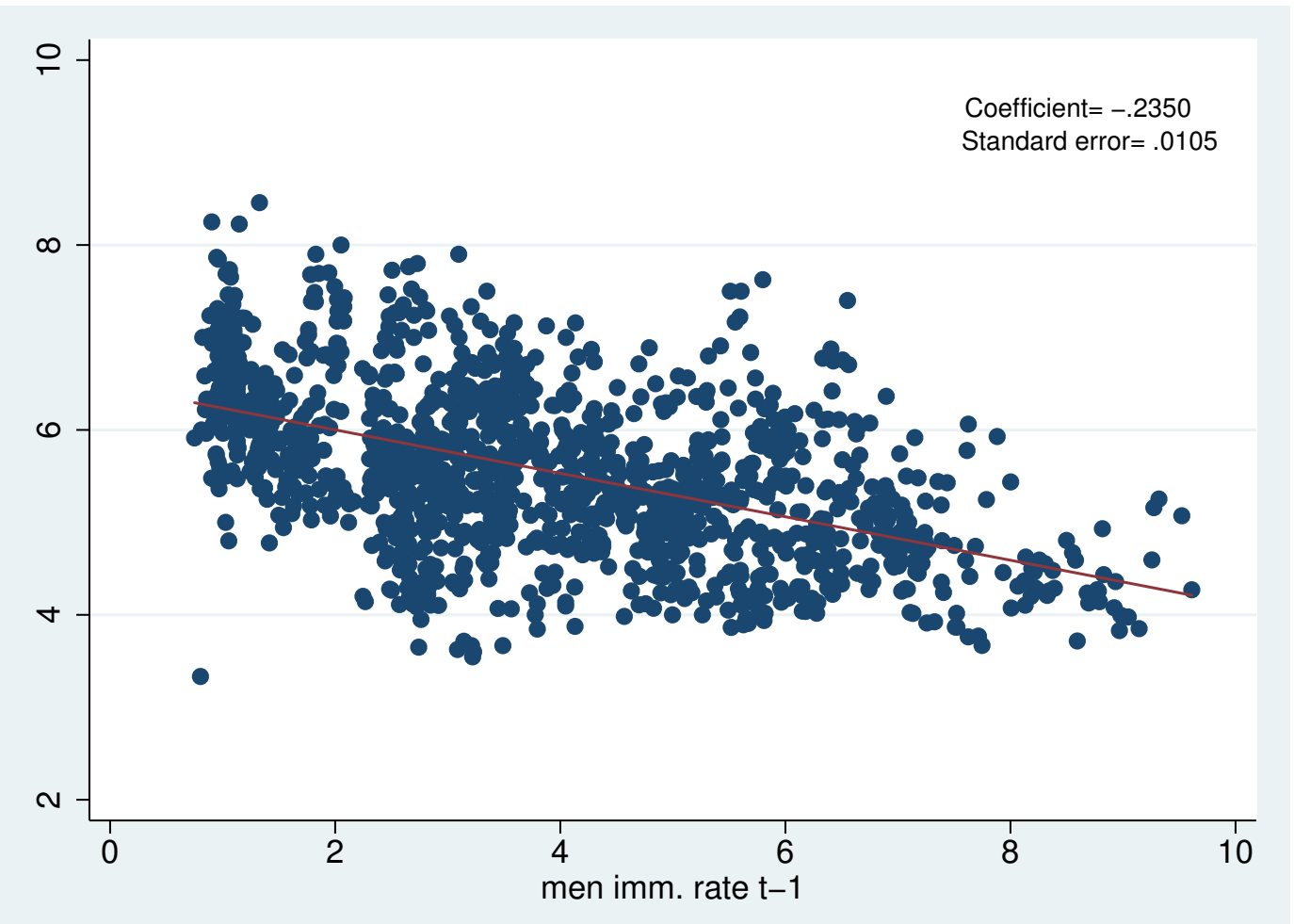

Notes - Data on immigration are drawn from the INKAR dataset (1996-2010). The average physical burden are obtained collapsing the information drawn from the SOEP (1996-2010) at the ROR level. 
Figure 4: Immigration and Disability status Across German RORs

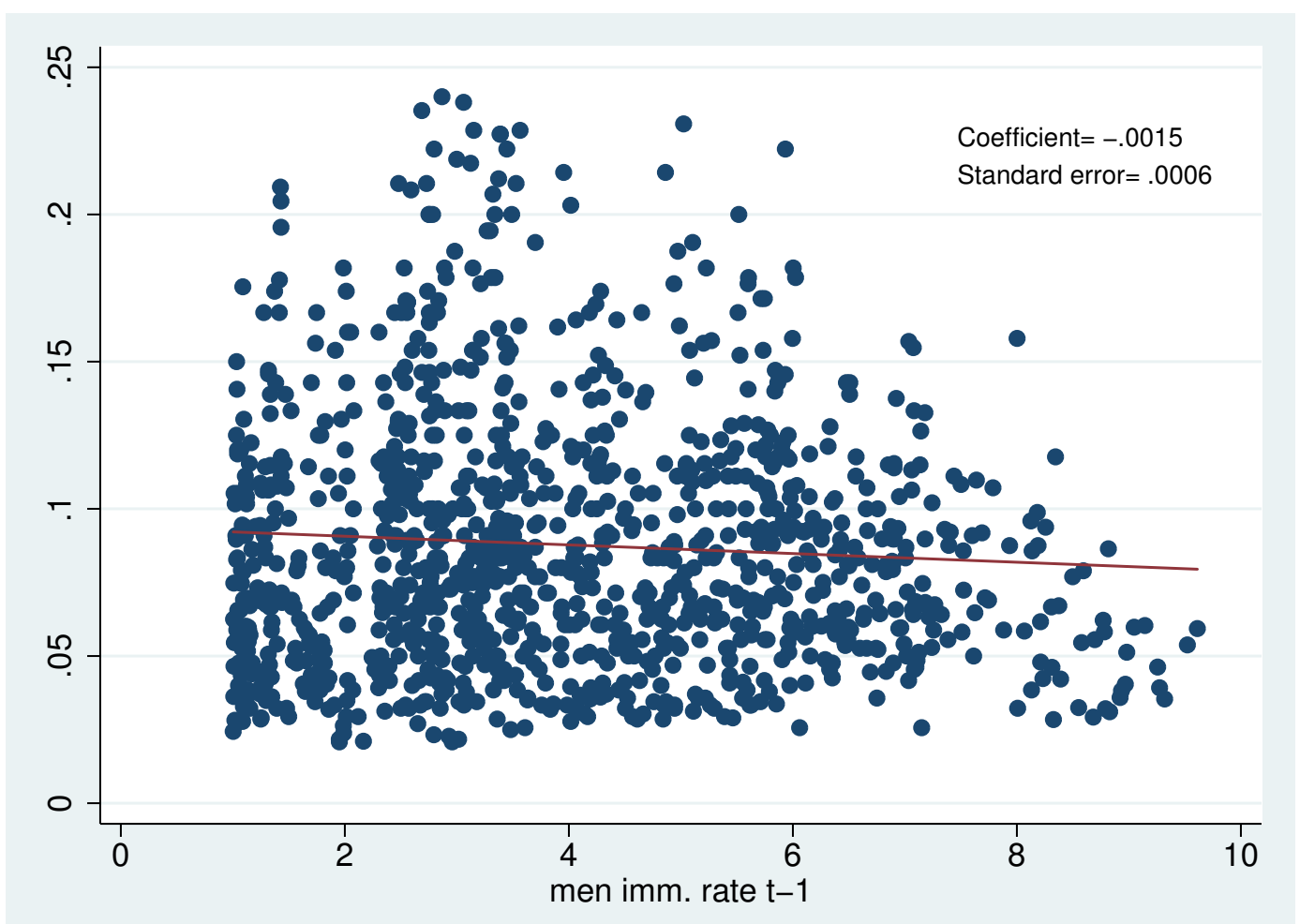

Notes - Data on immigration are drawn from the INKAR dataset (1996-2010). Data on average health status are obtained collapsing information drawn from the SOEP (1996-2010) at the ROR level. 
Table 1: Descriptive Statistics

\begin{tabular}{|c|c|c|c|c|}
\hline & (1) & (2) & (3) & (4) \\
\hline & \multicolumn{2}{|c|}{ Men } & \multicolumn{2}{|c|}{ Women } \\
\hline & Natives & Immigrants & Natives & Immigrants \\
\hline \multirow[t]{2}{*}{ Disable } & 0.0745 & 0.0731 & 0.0666 & 0.0466 \\
\hline & $(0.2626)$ & $(0.2603)$ & $(0.2494)$ & $(0.2107)$ \\
\hline \multirow[t]{2}{*}{ Severe health limitations } & 0.0796 & 0.0841 & 0.0486 & 0.0706 \\
\hline & $(0.2707)$ & $(0.2775)$ & $(0.2151)$ & $(0.2561)$ \\
\hline \multirow[t]{2}{*}{ Age } & 41.8507 & 42.0838 & 41.7019 & 41.5897 \\
\hline & $(9.7317)$ & $(9.7983)$ & $(9.6930)$ & $(9.6417)$ \\
\hline \multirow[t]{2}{*}{ Married } & 0.6584 & 0.8256 & 0.6862 & 0.8280 \\
\hline & $(0.4742)$ & $(0.3794)$ & $(0.4640)$ & $(0.3774)$ \\
\hline \multirow[t]{2}{*}{ High school degree } & 0.7453 & 0.7247 & 0.7828 & 0.6509 \\
\hline & $(0.4357)$ & $(0.4467)$ & $(0.4123)$ & $(0.4767)$ \\
\hline \multirow{2}{*}{ College degree } & 0.2310 & 0.1033 & 0.1934 & 0.1078 \\
\hline & $(0.4215)$ & $(0.3044)$ & $(0.3950)$ & $(0.3101)$ \\
\hline \multirow[t]{2}{*}{ Employed } & 0.8789 & 0.8293 & 0.6991 & 0.5568 \\
\hline & $(0.3263)$ & $(0.3762)$ & $(0.4587)$ & $(0.4968)$ \\
\hline \multirow{2}{*}{ Blue collar } & 0.3497 & 0.6145 & 0.0936 & 0.2493 \\
\hline & $(0.4769)$ & $(0.4867)$ & $(0.2912)$ & $(0.4326)$ \\
\hline \multirow[t]{2}{*}{ Years blue } & 3.1736 & 5.3556 & 0.8466 & 2.2100 \\
\hline & $(4.7803)$ & $(5.3240)$ & $(2.4292)$ & $(3.8869)$ \\
\hline \multirow[t]{2}{*}{ Physical burden } & 4.8009 & 6.3343 & 3.1794 & 3.5772 \\
\hline & $(3.3853)$ & $(3.6676)$ & $(2.9362)$ & $(3.7405)$ \\
\hline \multirow[t]{2}{*}{ Log wage } & 8.2641 & 8.1505 & 6.4190 & 5.1946 \\
\hline & $(4.0029)$ & $(3.8616)$ & $(4.5277)$ & $(4.6655)$ \\
\hline \multirow[t]{2}{*}{ Work. hours } & 44.5536 & 41.8615 & 33.0354 & 31.7746 \\
\hline & $(10.0246)$ & $(8.7575)$ & (13.1459) & $(12.4847)$ \\
\hline \multirow[t]{2}{*}{ Years since migration (YSM) } & & 20.1210 & & 19.2187 \\
\hline & & $(9.4216)$ & & $(9.5899)$ \\
\hline \multirow[t]{2}{*}{ Arrived before 1980} & & 0.5988 & & 0.5344 \\
\hline & & $(0.4901)$ & & $(0.4988)$ \\
\hline \multirow[t]{2}{*}{ Arrived 1980-1990 } & & 0.1777 & & 0.2085 \\
\hline & & $(0.3823)$ & & $(0.4063)$ \\
\hline \multirow[t]{2}{*}{ Arrived. after 1990} & & 0.2234 & & 0.2570 \\
\hline & & $(0.4166)$ & & $(0.4370)$ \\
\hline \multirow[t]{2}{*}{ Imm. rate } & 8.1346 & 10.9184 & 8.1544 & 10.9326 \\
\hline & $(4.7095)$ & $(3.6109)$ & $(4.6994)$ & $(3.6828)$ \\
\hline$N$ & 96.616 & 20,203 & 101,997 & 20,705 \\
\hline
\end{tabular}

Notes - Data are drawn from the GSOEP (1984-2010). 
Table 2: Men: Healthy Immigrant Effects by Occupation (assessed disability)

\begin{tabular}{|c|c|c|c|c|}
\hline & $(1)$ & $(2)$ & $(3)$ & $(4)$ \\
\hline & QFE & $\mathrm{FE}$ & QFE & $\mathrm{FE}$ \\
\hline Arrived before 1980 & $\begin{array}{c}-0.0623 * * * \\
(0.022)\end{array}$ & & $\begin{array}{c}-0.0883^{* * *} \\
(0.027)\end{array}$ & \\
\hline Arrived between 1980-1990 & $\begin{array}{c}-0.0570 * * * \\
(0.016)\end{array}$ & & $\begin{array}{c}-0.0902^{* * *} \\
(0.019)\end{array}$ & \\
\hline Arrived after 1980 & $\begin{array}{c}-0.0419 * * * \\
(0.013)\end{array}$ & & $\begin{array}{c}-0.0749^{* * *} \\
(0.016)\end{array}$ & \\
\hline YSM & $\begin{array}{c}0.0034^{* *} \\
(0.002)\end{array}$ & $\begin{array}{c}0.0038^{*} \\
(0.002)\end{array}$ & $\begin{array}{c}0.0054^{* * *} \\
(0.002)\end{array}$ & $\begin{array}{c}0.0058^{* * *} \\
(0.002)\end{array}$ \\
\hline Low physical burden *YSM & & & $\begin{array}{c}-0.0027 * * * \\
(0.001)\end{array}$ & $\begin{array}{c}-0.0031^{* * *} \\
(0.001)\end{array}$ \\
\hline Constant & $0.3408^{* * *}$ & & $0.2680^{* * *}$ & \\
\hline Mean of Dep. Var. & 0.0741 & 0.0741 & 0.0741 & 0.0741 \\
\hline Std. Dev. of Dep. Var. & 0.2621 & 0.2621 & 0.2621 & 0.2621 \\
\hline$N$ & 115,852 & 115,852 & 85,739 & 85,739 \\
\hline
\end{tabular}

Notes - All estimates include controls for age (quadratic), indicators for educational attainment (high drop outs, high-school and college graduate), marital status, and number of children, NUTS-2 fixed effects, and year fixed effects. Quasi fixed effects estimates (QFE) are random effect estimates augmented with the individual mean over time of the socio-demographic controls. Column 3 and 4 interact YSM with a dummy for people employed in low physical demanding jobs in the previous year ( Low PDJ). Standard errors are robust and clustered at individual level. 
Table 3: Effects of Immigration on Doctor-Assessed Disability

\begin{tabular}{|c|c|c|c|}
\hline & (1) & $(2)$ & (3) \\
\hline Panel A & & Men & \\
\hline & $\mathrm{FE}$ & $\mathrm{FE}$ & 2SLS \\
\hline$\%$ immigrants & $\begin{array}{l}-0.002 \text { ** } \\
(0.001)\end{array}$ & $\begin{array}{l}-0.002 \text { ** } \\
(0.001)\end{array}$ & $\begin{array}{l}-0.005^{*} \\
(0.003)\end{array}$ \\
\hline$F^{\dagger}$ & & & 52.15 \\
\hline$\%$ male immigrants & $\begin{array}{l}-0.005^{* *} \\
(0.002)\end{array}$ & $\begin{array}{l}-0.005^{* *} \\
(0.002)\end{array}$ & $\begin{array}{l}-0.010 * \\
(0.005)\end{array}$ \\
\hline$F^{\dagger}$ & & & 52.88 \\
\hline Mean of Dep. Var. & 0.0749 & 0.0749 & 0.0752 \\
\hline Std. Dev. of Dep. & 0.2632 & 0.2632 & 0.2637 \\
\hline$N$ & 69,654 & 69,654 & 63,966 \\
\hline Panel B & & Women & \\
\hline$\%$ immigrants & $\begin{array}{r}0.000 \\
(0.001)\end{array}$ & $\begin{array}{r}0.000 \\
(0.001)\end{array}$ & $\begin{array}{r}-0.000 \\
(0.002)\end{array}$ \\
\hline$F^{\dagger}$ & & & 47.19 \\
\hline$\%$ female immigrants & $\begin{array}{r}0.001 \\
(0.002)\end{array}$ & $\begin{array}{r}0.000 \\
(0.001)\end{array}$ & $\begin{array}{r}-0.001 \\
(0.004)\end{array}$ \\
\hline$F^{\dagger}$ & & & 50.78 \\
\hline Mean of Dep. Var. & 0.0670 & 0.0670 & 0.0674 \\
\hline Std. Dev. of Dep. & 0.2500 & 0.2500 & 0.2506 \\
\hline$N$ & 74,846 & 74,846 & 74,846 \\
\hline INDIVIDUAL F.E & YES & YES & YES \\
\hline YEAR F.E. & YES & YES & YES \\
\hline ROR-F.E. & YES & YES & YES \\
\hline ROR-trends & $\mathrm{NO}$ & YES & $\mathrm{NO}$ \\
\hline
\end{tabular}

Notes - All estimates include controls for age (quadratic), indicators for educational attainment (high drop outs, high-school and college graduate), marital status, and number of children, ROR fixed effects, year fixed effects, and local economic conditions at the ROR level.

$\mathrm{FE}=$ Fixed Effects model; 2SLS $=$ Two stage least squares. Standard errors are robust and clustered at ROR level ${ }^{\dagger} \mathrm{F}$-test on the excluded instrument. 
Table 4: Effect of Immigration on Doctor-Assessed Disability by Foreign-Born Status, Education and Occupational Type

\begin{tabular}{|c|c|c|c|c|c|c|}
\hline \multirow{4}{*}{ Panel A } & \multicolumn{6}{|c|}{ Nationality } \\
\hline & (1) & $(2)$ & $(3)$ & $(4)$ & (5) & (6) \\
\hline & \multicolumn{2}{|l|}{ All } & \multicolumn{2}{|c|}{ Natives } & \multicolumn{2}{|c|}{ Immigrants } \\
\hline & $\mathrm{FE}$ & $2 \mathrm{SLS}$ & $\mathrm{FE}$ & 2SLS & $\mathrm{FE}$ & 2SLS \\
\hline$\%$ male immigrants & $\begin{array}{l}-0.005^{* *} \\
(0.002)\end{array}$ & $\begin{array}{c}-0.010^{*} \\
(0.005)\end{array}$ & $\begin{array}{l}-0.003 * \\
(0.002)\end{array}$ & $\begin{array}{c}-0.009 * \\
(0.005)\end{array}$ & $\begin{array}{l}-0.013^{*} \\
(0.007)\end{array}$ & $\begin{array}{r}-0.013 \\
(0.033)\end{array}$ \\
\hline$F^{\dagger}$ & & 52.88 & & 55.17 & & 10.42 \\
\hline Mean of Dep. Var. & 0.0749 & 0.0749 & 0.0749 & 0.0749 & 0.0756 & 0.0756 \\
\hline Std. Dev. of Dep. Var & 0.2632 & 0.2632 & 0.2632 & 0.2632 & 0.2644 & 0.2644 \\
\hline$N$ & 69,654 & 63,966 & 59,729 & 55,194 & 9,825 & 8,692 \\
\hline \multirow[t]{3}{*}{ Panel B } & \multicolumn{6}{|c|}{ Education } \\
\hline & \multicolumn{2}{|c|}{ All } & \multicolumn{2}{|c|}{ No College } & \multicolumn{2}{|c|}{ College } \\
\hline & $\mathrm{FE}$ & 2SLS & $\mathrm{FE}$ & 2SLS & $\mathrm{FE}$ & 2SLS \\
\hline$\%$ male immigrants & $\begin{array}{l}-0.005^{* *} \\
(0.002)\end{array}$ & $\begin{array}{l}-0.010 * \\
(0.005)\end{array}$ & $\begin{array}{c}-0.005 * \\
(0.003)\end{array}$ & $\begin{array}{c}-0.015^{*} \\
(0.008)\end{array}$ & $\begin{array}{r}-0.001 \\
(0.001)\end{array}$ & $\begin{array}{r}-0.001 \\
(0.003)\end{array}$ \\
\hline$F^{\dagger}$ & & 52.88 & & 38.12 & & 65.44 \\
\hline Mean of Dep. Var. & 0.0749 & 0.0749 & 0.085 & 0.085 & 0.0409 & 0.0409 \\
\hline Std. Dev. of Dep. Var & 0.2632 & 0.2632 & 0.08529 & 0.08529 & 0.1980 & 0.1980 \\
\hline$N$ & 69,654 & 63,966 & 52,741 & 48,169 & 15,929 & 14,731 \\
\hline \multirow[t]{3}{*}{ Panel C } & \multicolumn{6}{|c|}{ Occupational Type: White vs Blue Collars } \\
\hline & \multicolumn{2}{|c|}{ All } & \multicolumn{2}{|c|}{ Blue Collars } & \multicolumn{2}{|c|}{ White Collars } \\
\hline & $\mathrm{FE}$ & 2SLS & $\mathrm{FE}$ & 2SLS & $\mathrm{FE}$ & 2SLS \\
\hline$\%$ male immigrants & $\begin{array}{r}-0.005^{* *} \\
(0.002)\end{array}$ & $\begin{array}{l}-0.010^{*} \\
(0.005)\end{array}$ & $\begin{array}{r}-0.008^{* *} \\
(0.003)\end{array}$ & $\begin{array}{c}-0.017^{*} \\
(0.010)\end{array}$ & $\begin{array}{r}-0.003 \\
(0.002)\end{array}$ & $\begin{array}{r}-0.003 \\
(0.006)\end{array}$ \\
\hline$F^{\dagger}$ & & 52.88 & & 56.34 & & 21.84 \\
\hline Mean of Dep. Var. & 0.0749 & 0.0749 & 0.0593 & 0.0593 & 0.0756 & 0.0756 \\
\hline Std. Dev. of Dep. Var & 0.2632 & 0.2632 & 0.2361 & 0.2361 & 0.2644 & 0.2644 \\
\hline$N$ & 69,654 & 63,966 & 26,310 & 23,499 & 32,169 & 29,599 \\
\hline
\end{tabular}

Notes - All estimates include controls for age (quadratic), indicators for educational attainment (high drop outs, high-school and college graduate) marital status, and number of children, ROR fixed effects, year fixed effects, and local economic conditions at the ROR level. Standard errors are robust and clustered at ROR level ${ }^{\dagger}$ F-test on the excluded instrument. 
Table 5: Effect of Immigration on Physical Burden (Men)

\begin{tabular}{|c|c|c|c|c|c|c|}
\hline & $(1)$ & $(2)$ & $(3)$ & $(4)$ & $(5)$ & $(6)$ \\
\hline & \multicolumn{3}{|c|}{$1996-2010$} & \multirow{2}{*}{\multicolumn{3}{|c|}{$\begin{array}{c}2001 \\
\text { Perceived physical burden }\end{array}$}} \\
\hline & Blue collar & Physica & l burden & & & \\
\hline$\%$ male immigrants & $\begin{array}{c}0.002 \\
(0.003)\end{array}$ & $\begin{array}{l}-0.002 \\
(0.014)\end{array}$ & $\begin{array}{c}0.003 \\
(0.015)\end{array}$ & $\begin{array}{c}-0.015^{* *} \\
(0.007)\end{array}$ & $\begin{array}{l}-0.006 \\
(0.007)\end{array}$ & $\begin{array}{l}-0.005 \\
(0.007)\end{array}$ \\
\hline$\%$ male immigrants *blue & & & $\begin{array}{c}-0.050^{* *} \\
(0.022)\end{array}$ & & $\begin{array}{c}-0.019^{* * *} \\
(0.004)\end{array}$ & $\begin{array}{c}-0.018^{* * *} \\
(0.004)\end{array}$ \\
\hline Blue collar & & & $\begin{array}{c}1.915^{* * *} \\
(0.110)\end{array}$ & & $\begin{array}{c}0.314^{* * *} \\
(0.023)\end{array}$ & $\begin{array}{c}0.115^{* * *} \\
(0.026)\end{array}$ \\
\hline Mean of Dep. Var. & 5.6926 & 5.6926 & 5.6926 & 0.1954 & 0.1900 & 0.1900 \\
\hline Std. Dev. of Dep. Var & 3.0772 & 3.0772 & 3.0772 & 0.3966 & 0.3924 & 0.3924 \\
\hline$N$ & 59,645 & 58,855 & 55,169 & 5,721 & 5,404 & 5,404 \\
\hline ROR FE & YES & YES & YES & $\mathrm{NO}$ & NO & NO \\
\hline NUTS1 FE & NO & NO & NO & YES & YES & YES \\
\hline Physical burden FE & NO & NO & NO & NO & NO & YES \\
\hline INDIVIDUAL FE & YES & YES & YES & NO & $\mathrm{NO}$ & NO \\
\hline
\end{tabular}

Notes - All estimates include controls for age (quadratic), indicators for educational attainment (high drop outs, high-school and college graduate), marital status, and number of children, ROR fixed effects, year fixed effects, and local economic conditions at the ROR level. Columns 1-3 report the estimates obtained using the within estimator (FE) including ROR and survey year fixed effects. The dependent variable in column 1 is a an indicator for whether the worker reported being employed in a blue-collar occupation; in columns 2 and 3 the dependent variable is the physical burden index associated with a given occupation; in column 4, 5, and 6 the dependent variable is the perceived physical burden. In column 3 , the effect of immigration rate is interacted with the blue collar dummy. Columns 4, 5 and 6 control for NUTS- 1 fixed effects. Column 6 includes a full set of dummies for the value of physical burden index. Standard errors are robust and clustered at ROR level. 
Table 6: Effects of Immigration on Labor Market and Working Conditions

\begin{tabular}{lcccccc}
\hline \hline & $(1)$ & $(2)$ & $(3)$ & $(4)$ & $(5)$ & $(6)$ \\
\hline Dep.Var: & Employment Status & $\log$ (Wage) & \# Hours Worked & Overtime & Night Shift & Health Concerns \\
\hline \% male immigrants & 0.002 & $0.016^{*}$ & $-0.268^{* *}$ & $-0.011^{*}$ & -0.010 & $-0.011^{* *}$ \\
& $(0.003)$ & $(0.009)$ & $(0.123)$ & $(0.006)$ & $(0.012)$ & $(0.005)$ \\
& & & & & & \\
& & & & & & \\
& & & & & & \\
Mean of Dep. Var. & 0.8654 & 8.1931 & 44.6063 & 0.5797 & 0.3885 & 0.4813 \\
Std. Err. of Dep. Var. & 0.3412 & 4.1133 & 10.4184 & 0.4936 & 0.4874 & 61,287 \\
N & 70,009 & 70,009 & 59,012 & 50,864 & 17,131 & \\
\hline \hline
\end{tabular}

Notes - All estimates include controls for age (quadratic), indicators for educational attainment (high drop outs, high-school and college graduate), marital status, and number of children, ROR fixed effects, year fixed effects, and local economic conditions at the ROR level. All models include individual fixed-effects. Standard errors are robust and clustered at ROR level. 


\section{Appendix A}

Table A.1: Women: Healthy Immigrant Effects by occupation (assessed disability)

\begin{tabular}{lcccc}
\hline \hline & $(1)$ & $(2)$ & $(3)$ & $(4)$ \\
\hline & QFE & FE & QFE & FE \\
\hline Arrived before 1980 & $-0.0406^{* *}$ & & -0.0337 & \\
& $(0.018)$ & $(0.023)$ & \\
& & & & \\
Arrived 1980-1990 & $-0.0345^{* * *}$ & $-0.0372^{* * *}$ & \\
& $(0.013)$ & $(0.018)$ & \\
Arrived after 1990 & $-0.0242^{* *}$ & & $-0.0290^{* * *}$ & \\
& $(0.010)$ & & $(0.013)$ & \\
YSM & 0.0004 & 0.0003 & 0.0010 & 0.0009 \\
& $(0.001)$ & $(0.002)$ & $(0.002)$ & $(0.002)$ \\
Low physical burden*YSM & & & -0.0001 & -0.0001 \\
& & & $(0.001)$ & $(0.001)$ \\
Constant & & & $0.2438^{* * *}$ & \\
& $0.3066^{* * *}$ & & & \\
\hline
\end{tabular}

Mean of Dep. Var.

Std. Dev. of Dep. Var.

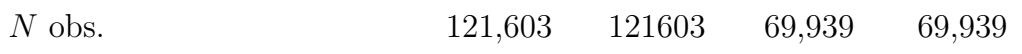

Notes - All estimates include controls for age (quadratic), indicators for educational attainment (high drop outs, high-school and college graduate), marital status, and number of children, NUTS-2 fixed effects, and year fixed effects. Quasi fixed effects estimates (QFE) are random effect estimates augmented with the individual mean over time of the socio-demographic controls. Column 3 and 4 interact YSM with a dummy for people employed in low physical demanding jobs in the previous year ( Low PDJ). Standard errors are robust and clustered at individual level. 
Table A.2: Immigrants by Arrival Cohort, Country of Origin and Education

\begin{tabular}{|c|c|c|c|c|c|c|}
\hline & $(1)$ & $(2)$ & $(3)$ & $(4)$ & $(5)$ & $(6)$ \\
\hline & \multicolumn{2}{|c|}{ Arrived before 1980} & \multicolumn{2}{|c|}{ Arrived 1980-1990 } & \multicolumn{2}{|c|}{ Arrived after 1990} \\
\hline Origin & Education & $\%$ & Education & $\%$ & Education & $\%$ \\
\hline Turkish & 9.217 & 30.346 & 9.410 & 27.230 & 9.596 & 13.867 \\
\hline Mediterranean & 9.243 & 34.805 & 9.588 & 10.139 & 10.052 & 8.264 \\
\hline Balkan & 9.745 & 18.237 & 9.666 & 6.701 & 10.808 & 9.347 \\
\hline East and Russia & 11.291 & 7.356 & 11.507 & 40.846 & 11.020 & 48.802 \\
\hline Other & 12.162 & 9.256 & 12.342 & 15.084 & 11.797 & 19.720 \\
\hline Germans* & 10.989 & & 11.310 & & 12.124 & \\
\hline
\end{tabular}

Notes - For immigrants who arrived before 1980, we consider Germans who were over 40 in the waves 1985-1989 as a reference group; for immigrants arrived between 1980 and 1989, we consider all Germans aged 25-59 in the waves 1985-1989; for immigrants arrived after 1989, we consider all Germans (aged 25-59) in the waves 1990-2010. 
Table A.3: Immigrant Occupational Sorting

\begin{tabular}{|c|c|c|c|c|}
\hline & (1) & $(2)$ & $(3)$ & $(4)$ \\
\hline & \multicolumn{2}{|l|}{ Men } & \multicolumn{2}{|c|}{ Women } \\
\hline & Physical burden & Blue collar & Physical burden & Blue collar \\
\hline Arrived before 1980 & $\begin{array}{c}1.9119^{* * *} \\
(0.070)\end{array}$ & $\begin{array}{c}0.2265^{* * *} \\
(0.012)\end{array}$ & $\begin{array}{c}1.7988^{* * *} \\
(0.082)\end{array}$ & $\begin{array}{c}0.1848^{* * *} \\
(0.012)\end{array}$ \\
\hline Arrived 1980-1990 & $\begin{array}{c}1.5290^{* * *} \\
(0.108)\end{array}$ & $\begin{array}{c}0.1982^{* * *} \\
(0.018)\end{array}$ & $\begin{array}{c}1.3855^{* * *} \\
(0.122)\end{array}$ & $\begin{array}{c}0.0793^{* * *} \\
(0.013)\end{array}$ \\
\hline Arrived after 1990 & $\begin{array}{c}0.9980^{* * *} \\
(0.084)\end{array}$ & $\begin{array}{c}0.0903^{* * *} \\
(0.013)\end{array}$ & $\begin{array}{c}1.0954^{* * *} \\
(0.085)\end{array}$ & $\begin{array}{c}0.0740^{* * *} \\
(0.009)\end{array}$ \\
\hline Constant & $8.1986^{* * *}$ & $0.2079^{* * *}$ & $5.1168 * * *$ & $0.1533^{* * *}$ \\
\hline Mean of Dep. Var. & 5.9167 & 0.4162 & 4.9122 & 0.127 \\
\hline Std. Dev. of Dep. Var & 3.0612 & 0.4929 & 2.5280 & 0.3330 \\
\hline$N$ & 110,101 & 128,491 & 87,986 & 134,157 \\
\hline
\end{tabular}

Notes - All estimates include controls for age (quadratic), indicators for educational attainment (high drop outs, high-school and college graduate), marital status, and number of children, NUTS-2 fixed effects, and year fixed effects. Standard errors are robust and clustered at individual level.The model is estimated using the random effect estimator. 
Table A.4: Robustness checks: Timing of the Effect of Immigration

\begin{tabular}{|c|c|c|c|c|c|}
\hline & (1) & $(2)$ & $(3)$ & (4) & (5) \\
\hline & \multicolumn{5}{|c|}{$\mathrm{FE}$} \\
\hline Time: & $t+1$ & $\mathrm{t}$ & $\mathrm{t}-1$ & $\mathrm{t}-2$ & $t-3$ \\
\hline Male imm. rate & $\begin{array}{r}0.002 \\
(0.002)\end{array}$ & $\begin{array}{r}-0.006 \\
(0.008)\end{array}$ & $\begin{array}{l}-0.005^{* *} \\
(0.002)\end{array}$ & $\begin{array}{l}-0.005^{* *} \\
(0.002)\end{array}$ & $\begin{array}{l}-0.004^{* *} \\
(0.002)\end{array}$ \\
\hline \multirow[t]{2}{*}{$N$} & 70,789 & 77,776 & 69,654 & 60,369 & 51,679 \\
\hline & \multicolumn{5}{|c|}{ 2SLS } \\
\hline Male imm. rate & $\begin{array}{r}-0.002 \\
(0.008)\end{array}$ & $\begin{array}{r}-0.015 \\
(0.058)\end{array}$ & $\begin{array}{l}-0.011^{* *} \\
(0.003)\end{array}$ & $\begin{array}{l}-0.009 * * * \\
(0.003)\end{array}$ & $\begin{array}{l}-0.006 \text { ** } \\
(0.002)\end{array}$ \\
\hline $\mathrm{N}$ & 68,936 & 74,947 & 63,966 & 55,134 & 46,436 \\
\hline INDIVIDUAL F.E & YES & YES & YES & YES & YES \\
\hline YEAR F.E. & YES & YES & YES & YES & YES \\
\hline NUTS2-F.E & YES & YES & YES & YES & YES \\
\hline
\end{tabular}

Notes - All estimates include controls for age (quadratic), indicators for educational attainment (high drop outs, high-school and college graduate), marital status, and number of children, ROR fixed effects, year fixed effects, and local economic conditions at the ROR level. 
Table A.5: Robustness Checks: Effects of Immigration on Poor Health

\begin{tabular}{|c|c|c|c|c|c|c|}
\hline & (1) & $(2)$ & (3) & (4) & (5) & (6) \\
\hline Panel A & \multicolumn{6}{|c|}{ Nationality } \\
\hline & \multicolumn{2}{|c|}{ All } & \multicolumn{2}{|c|}{ Natives } & \multicolumn{2}{|c|}{ Immigrants } \\
\hline & $\mathrm{FE}$ & 2SLS & $\mathrm{FE}$ & 2SLS & $\mathrm{FE}$ & 2SLS \\
\hline$\%$ male immigrants & $\begin{array}{c}-0.004 \\
(0.003)\end{array}$ & $\begin{array}{l}-0.013^{*} \\
(0.007)\end{array}$ & $\begin{array}{r}-0.003 \\
(0.003)\end{array}$ & $\begin{array}{l}-0.012^{*} \\
(0.007)\end{array}$ & $\begin{array}{r}-0.015 \\
(0.011)\end{array}$ & $\begin{array}{r}-0.018 \\
(0.043)\end{array}$ \\
\hline$N$ & 69,890 & 64,172 & 59,932 & 55,377 & 9,858 & 8,715 \\
\hline Panel B & \multicolumn{6}{|c|}{ Education } \\
\hline & \multicolumn{2}{|c|}{ All } & \multicolumn{2}{|c|}{ No College } & \multicolumn{2}{|c|}{ College } \\
\hline$\%$ male immigrants & $\begin{array}{l}-0.004 * \\
(0.003)\end{array}$ & $\begin{array}{l}-0.013^{*} \\
(0.007)\end{array}$ & $\begin{array}{c}-0.004 \\
(0.004)\end{array}$ & $\begin{array}{r}-0.015 \\
(0.011)\end{array}$ & $\begin{array}{r}-0.001 \\
(0.003)\end{array}$ & $\begin{array}{r}-0.011 \\
(0.007)\end{array}$ \\
\hline$N$ & 69,890 & 64,172 & 52,953 & 48,358 & 15,944 & 14,744 \\
\hline
\end{tabular}

Notes - All estimates include controls for age (quadratic), indicators for educational attainment (high drop outs, high-school and college graduate), marital status, and number of children, ROR fixed effects, year fixed effects, and local economic conditions at the ROR level. Standard errors are robust and clustered at ROR level. 
Table A.6: Robustness Checks: Correlated Random Effect Probit Model

\begin{tabular}{|c|c|c|c|}
\hline & $(1)$ & $(2)$ & $(3)$ \\
\hline Panel A & \multicolumn{3}{|c|}{ Nationality } \\
\hline & All & Natives & Immigrants \\
\hline$\%$ male immigrants & $\begin{array}{l}-0.003^{* *} \\
(0.001)\end{array}$ & $\begin{array}{c}-0.002^{*} \\
(0.001)\end{array}$ & $\begin{array}{r}-0.005 \\
(0.003)\end{array}$ \\
\hline$N$ & 69,654 & 59,650 & 9,806 \\
\hline Panel B & \multicolumn{3}{|c|}{ Education } \\
\hline & All & No College & College \\
\hline$\%$ male immigrants & $\begin{array}{l}-0.003^{* *} \\
(0.002)\end{array}$ & $\begin{array}{l}-0.012 * \\
(0.005)\end{array}$ & $\begin{array}{r}0.003 \\
(0.003)\end{array}$ \\
\hline$N$ & 69,654 & 52,741 & 15,929 \\
\hline
\end{tabular}

Notes - All estimates include controls for age (quadratic), indicators for educational attainment (high drop outs, high-school and college graduate), marital status, and number of children, ROR fixed effects, year fixed effects, and local economic conditions at the ROR level. Estimated using correlated random effect probit model which also include mean value of the demographics. The reported coefficient are average partial effects (APE). Standard errors are robust and clustered at ROR level. 